05

\title{
Некоторые особенности регистрации спектра конденсированной среды методом ядерного магнитного резонанса в слабом поле
}

\author{
(C) В.В. Давыдов ${ }^{1,2,3}$, Н.С. Мязин ${ }^{1}$, Е.Н. Величко ${ }^{1}$ \\ ${ }^{1}$ Санкт-Петербургский политехнический университет Петра Великого \\ ${ }^{2}$ Санкт-Петербургский государственный университет телекоммуникаций \\ им. проф. М.А. Бонч-Бруевича \\ ${ }^{3}$ Всероссийский научно-исследовательский институт фритопатологии, \\ Московская область \\ E-mail: Davydov_vadim66@mail.ru
}

Поступило в Редакцию 29 декабря 2016 г.

Рассмотрены особенности регистрации сигналов ядерного магнитного резонанса в слабом магнитном поле от малого объема исследуемой среды. Учет установленных нами особенностей в новой разработанной конструкции магнитной системы для малогабаритного ядерно-магнитного спектрометра, а также в методике регистрации сигнала ЯМР позволяет значительно расширить возможности применения явления ядерного магнитного резонанса для исследования конденсированных сред в экспресс-режиме. Представлены результаты экспериментальных исследований различных сред.

DOI: $10.21883 /$ PJTF.2017.13.44809.16654

В настоящее время одним из актуальных направлений физики конденсированных сред является разработка быстрых и надежных методов их исследования в экспресс-режиме [1-3]. Данные исследования особенно востребованы для контроля состояния среды перед проведением различных физических и химических экспериментов после ее длительного хранения или транспортировки, во время экологического мониторинга труднодоступных мест водных объектов и их прибрежных зон, а также в случаях контроля качества продукции и т.д. [2-4].

Одним из основных достоинств измерителей, принцип работы которых основан на явлении ядерного магнитного резонанса (ЯМР) [5-9], является то, что проведенные с их помощью исследования не вы- 
зывают изменений в химическом составе и физической структуре пробы конденсированной среды. Это первостепенное из требований, которые сейчас предъявляются к методам экспресс-контроля [1,4,9-11]. Выполнение данного требования позволяет получать подтверждения выявленного отклонения в пробе разработанными малогабаритными ЯМР-измерителями (релаксометрами) при дальнейшем ее исследовании в спектрометрах высокого разрешения в стационарных лабораториях, что особенно важно, например, при таможенном контроле или проверке качества продукции. Данный факт делает эти приборы очень востребованными для экспресс-контроля.

Но разработанные ранее малогабаритные ЯМР-измерители [4,11], как показали проведенные нами исследования, имеют ряд ограничений в работе, связанных с регистрацией сигнала ЯМР от малого объема $\left(V_{R} \leqslant 0.2 \mathrm{ml}\right)$ исследуемой среды в магнитных полях с индукцией $B_{0} \leqslant 0.15 \mathrm{~T}$, называемых в ядерно-магнитной спектрометрии слабыми по отношению к полям стационарных ЯМР-спектрометров, в которых значения $B_{0}$ изменяются от 7 до $40 \mathrm{~T}$ [1-3]. Поэтому, чтобы сохранить достаточно широкий диапазон их применения, они были настроены на частоту регистрации сигналов ЯМР от протонов $f_{p}$ (что соответствует гиромагнитному соотношению $\gamma=42.57637513 \mathrm{MHz} / \mathrm{T})$. Это являлось единственным эффективным решением, так как более $85 \%$ жидких сред содержат в своем составе протоны, обладающие наибольшей чувствительностью к методу ЯМР по сравнению с другими ядрами, содержащими магнитный момент [1,3,4,10-15]. Контроль состояния остальных сред, в которых отсутствовали протоны, с их использованием проводить было достаточно сложно. Кроме того, во время экспрессисследования конденсированных сред часто стали возникать задачи по определению относительных концентраций их компонентов (например, $\mathrm{NaCl})$, их кислотности $(\mathrm{pH})$ и т.д.

Поэтому целью работы является разработка новой малогабаритной магнитной системы, определение особенностей, возникающих при регистрации сигналов ЯМР в слабых магнитных полях от малого $V_{R}$, и учет их в конструкции ЯМР-спектрометра для получения возможности исследования спектрального состава среды в экспресс-режиме.

Для исследования конденсированных сред в экспресс-режиме был собран макет малогабаритного ЯМР-спектрометра, его структурная схема представлена на рис. 1. Новая магнитная система была изготовлена на основе магнитов в форме диска 1 из материала $(\mathrm{Nd}-\mathrm{Fe}-\mathrm{B})$,

$3^{*}$ Письма в ЖТФ, 2017, том 43, вып. 13 


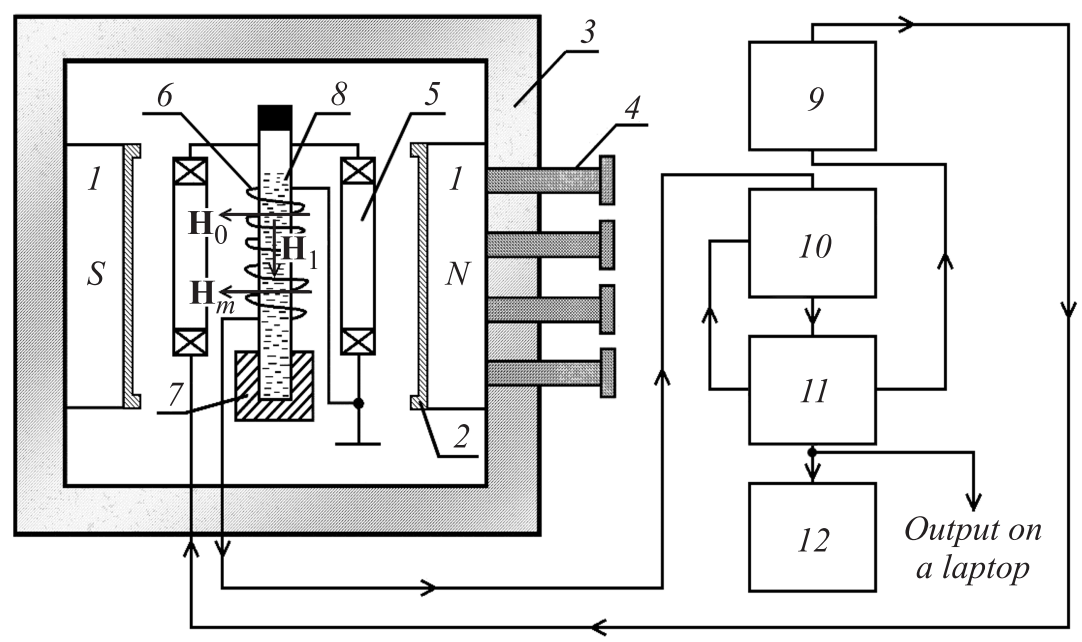

Рис. 1. Структурная схема малогабаритного ЯМР-спектрометра: 1 - постоянный магнит; 2 - вставки (шиммы); 3 - нейтраль для размещения и центровки магнитов; 4 - регулировочные винты; 5 - катушки модуляции; 6 - катушка регистрации сигнала ЯМР; 7 - фиксирующее устройство для контейнера с исследуемой средой; 8 - контейнер с исследуемой средой; 9 - радиочастотный генератор; 10 - автодинный детектор; $11-$ устройство обработки и управления; $12-$ осциллограф.

обладающего большой остаточной индукцией. Уменьшение степени неоднородности магнитного поля $B_{0}$, а также увеличение значения ее индукции удалось достичь размещением на полюсах магнитов 1 вставок 2 в виде ступенек (шиммов) из мягкого магнитного материала (Армко-железо). В разработанной конструкции механическая юстировка взаимного расположения полюсных наконечников 1 осуществляется с помощью регулировочных винтов 4. Это позволило в новой магнитной системе при диаметре полюсов $d_{p}=92 \mathrm{~mm}$ и расстоянии между ними $d_{s}=26 \mathrm{~mm}$ (размер вставки $92 \times 8 \mathrm{~mm}$ ) обеспечить неоднородность магнитного поля $10^{-4} \mathrm{~cm}^{-1}$ при $B_{0}=0.134 \mathrm{~T}$. Вес магнитной системы с катушками модуляции 5 и регистрации 6 , а также фиксирующим устройством контейнера 7 составил не более $3.9 \mathrm{~kg}$.

Письма в ЖТФ, 2017, том 43, вып. 13 
Проведенные исследования показали, что регистрация сигналов ЯМР в магнитных полях с $B_{0} \leqslant 0.15 \mathrm{~T}$ от малого $V_{R}$ может осуществляться только с помощью модуляционной методики $[1,4,7,13]$. Для ее реализации была разработана и собрана новая схема автодинного детектора 10 на основе малошумящих дифференциальных усилителей, что обеспечило его стабильную работу и подавление синфазных помех. Схема обработки и управления 11 была разработана и реализована на основе микроконтроллера STM32. Она осуществляет подстройку частоты регистрации $f_{n m r}$ и уровня генерации (поле $H_{1}$ ) автодинного детектора для обеспечения максимального отношения сигнал/шум $(S / N)$.

На рис. 2 в качестве примера представлены зарегистрированные сигналы ЯМР от соляной кислоты $\mathrm{HCl}$ по ядрам хлора. В ранее разработанном малогабаритном ЯМР-релаксометре $[4,11]$ исследование в экспресс-режиме $\mathrm{HCl}$ с использованием сигнала ЯМР было возможно только на резонансной частоте $f_{p}$ протонов. Анализ представленных на рис. 2 сигналов ЯМР показывает, что при их регистрации на резонансной частоте $f_{n m r}$ ядер хлора отношение $S / N>1.3$. Это позволяет осуществлять при регистрации сигнала ЯМР автоматическую подстройку частоты (АПЧ) $f_{n m r}$ на резонанс $[1,2,4-6]$. Но отношение $S / N<3.0$ (рис. 2,a), на пиках также присутствуют шумы. Проводить в таких условиях измерения констант релаксации с погрешностью не выше $1.0 \%$ для определения состояния среды невозможно [1-4,8-13]. Последующее накопление сигнала ЯМР позволяет получить отношение $S / N>10.0$ (рис. $2, b$ ), а также форму сигнала, обеспечивающие измерение времен продольной $T_{1}$ и поперечной $T_{2}$ релаксации с необходимой точностью.

Полученный результат показал, что использование разработанной нами магнитной системы, а также модернизированных электронных схем автодина и обработки сигнала ЯМР позволило реализовать в малогабаритном ЯМР-спектрометре перестройку частоты $f_{n m r}$ для регистрации сигналов ЯМР от ядер фтора, фосфора, лития, бора, натрия, хлора, марганца, свинца, ртути и т.д. Проведенные экспериментальные исследования показали, что если в исследуемой среде количество ядер $N_{\mathrm{F}}$ фтора превышает $N_{p}$ протонов в 1.5 раза, то сигнал ЯМР надо регистрировать от ядер фтора, так как в этом случае отношение $S / N$ от них в 1.3 раза выше, чем от протонов. От ядер лития сигнал ЯМР следует регистрировать, если в среде $N_{\mathrm{Li}}>N_{p} / 4$, для ядер натрия - $N_{\mathrm{Na}}>N_{p} / 12$. Для сред, в которых протоны отсутствуют, установленные нами соотношения между концентрациями

Письма в ЖТФ, 2017, том 43, вып. 13 

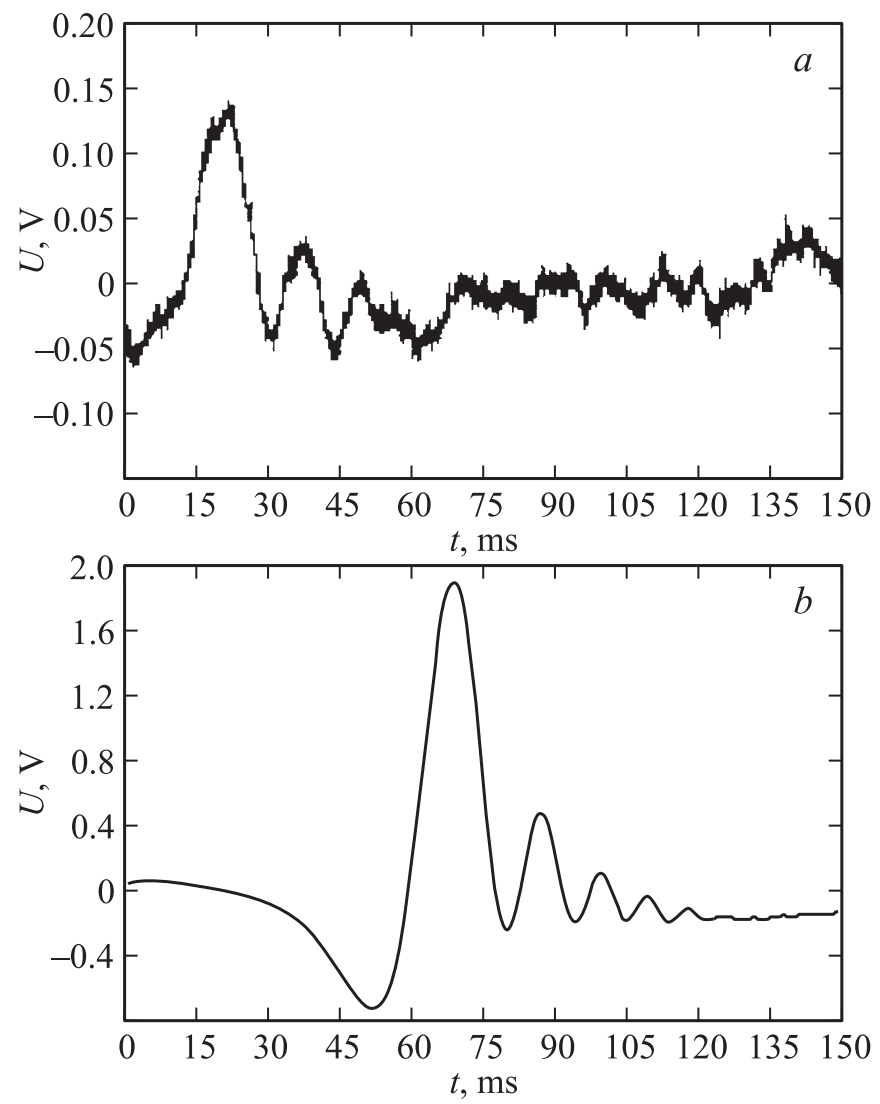

Рис. 2. Регистрируемый сигнал ЯМР от соляной кислоты при $T=291.3 \mathrm{~K}: a-$ без накопления; $b-$ на выходе схемы накопления.

ядер с магнитными моментами также необходимо учитывать при регистрации сигнала ЯМР для получения $S / N>1.3$, которое позволяет использовать для настройки $f_{n m r}$ на резонанс схему АПЧ. Например, в новой разработанной конструкции малогабаритного ЯМР-спектрометра сигнал ЯМР от хлорида железа $3\left(\mathrm{FeCl}_{3}\right)$ можно регистрировать только по ядрам хлора. Так как в силу малости $V_{R}$ регистрируемые 
сигналы ЯМР от других ядер будут в большинстве случаев обладать отношением $S / N<1.3$, что не позволяет использовать схему АПЧ на резонансную $f_{n m r}$ с последующей синхронизацией регистрируемого сигнала ЯМР для его накопления, чтобы проводить измерения с необходимой точностью $[1,4,11,15]$. Это является одной из особенностей регистрации сигналов ЯМР в слабых полях спектрометра при экспрессконтроле им состояния конденсированных сред.

Поэтому в разработанной нами конструкции ЯМР-спектрометра, учитывая эту особенность, был достигнут оптимум между значениями $B_{0}, \Delta B_{0}$ (неоднородность магнитного поля), регулируя расстояние между полюсами 1 и их взаимное расположение и $V_{R}$ по максимальной величине отношения $S / N$. Кроме того, проведенные экспериментальные исследования показали, что для регистрации сигнала ЯМР в магнитном поле с $B_{0} \leqslant 0.15 \mathrm{~T}$ с использованием модуляционной методики должно выполняться следующее соотношение:

$$
\gamma H_{m}>10 \Delta f_{n m r},
$$

где $H_{m}$ - амплитуда поля модуляции.

Полученное соотношение (1) накладывает ряд ограничений как на размер и конфигурацию катушек модуляции 5, так и на значение $H_{m}$, что необходимо учитывать в конструкции малогабаритного ЯМР-спектрометра. Это является еще одной особенностью регистрации сигнала ЯМР в слабом магнитном поле спектрометра. Экспериментально также было установлено, что для проведения измерения времени поперечной релаксации $T_{2}$ по спаду огибающей регистрируемого сигнала ЯМР с погрешностью менее $1.0 \%$ необходимо также выполнение следующего соотношения:

$$
T_{m}>5 T_{2},
$$

где $T_{m}=1 / f_{m}-$ период модуляции поля $B_{0}$.

Установленное нами соотношение (2) является еще одной особенностью регистрации сигнала ЯМР в слабых магнитных полях. Проведенные исследования жидких сред с различными константами релаксации при одинаковой температуре в лаборатории показали, что уменьшение частоты модуляции $f_{m}$, чтобы обеспечить выполнение (2) в случае регистрации сигналов ЯМР от сред с большим $T_{2}$, приводит к уменьшению отношения $S / N$, которое до определенного момента можно компенсировать увеличением $H_{1}$ (амплитуда поля в катушке

Письма в ЖТФ, 2017, том 43, вып. 13 

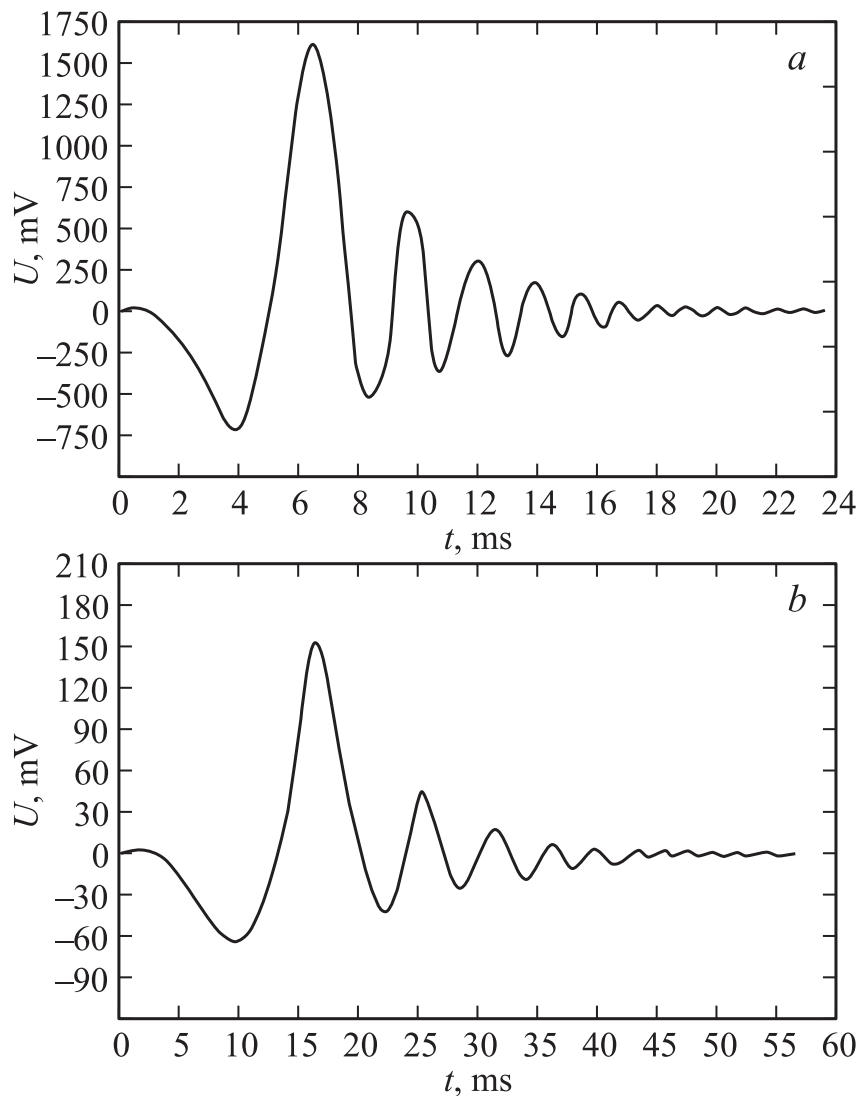

Рис. 3. Регистрируемый сигнал ЯМР от водного раствора гидроксида натрия: $a-$ от протонов; $b-$ от ядер натрия на выходе схемы накопления.

регистрации) и $H_{m}$. Но так как размер катушек регистрации и модуляции ограничен по причине жестких требований к массогабаритным характеристикам магнитной системы для сохранения мобильности малогабаритного ЯМР-спектрометра, то это приводит к ограничению возможностей по исследованию им конденсированных сред, что также является еще одной особенностью данного метода.

Письма в ЖТФ, 2017, том 43, вып. 13 
На рис. 3 в качестве примера представлены зарегистрированные сигналы ЯМР на протонах и ядрах натрия водного раствора $\mathrm{NaOH}$ при $T=281.6 \mathrm{~K}$, частота $f_{m}=5 \mathrm{~Hz}$. Схема накопления сигнала ЯМР (100 накоплений) использовалась только при регистрации сигнала ЯМР по ядрам натрия (рис. $3, b$ ). Полученные экспериментальные результаты показывают, что в отличие от спектрометров высокого разрешения $\left(B_{0}>7 \mathrm{~T}\right)$ большое значение $\gamma$ или магнитного момента ядра $\mu$ при малом $V_{R}$ и слабом поле $B_{0}$ не гарантирует регистрацию сигнала ЯМР от этих ядер по сравнению с ядрами с меньшим $\gamma$.

Например, в спектрометрах высокого разрешения с $B_{0}>7 \mathrm{~T}$ наибольшее применение получила спектроскопия на ядрах углерода $13\left({ }^{13} \mathrm{C}\right)$ и азота - $15\left({ }^{15} \mathrm{~N}\right)[1-4,9]$, а в слабых магнитных полях зарегистрировать от них сигнал ЯМР - трудно реализуемая задача в отличие от ядер хлора $-37\left({ }^{37} \mathrm{Cl}\right)$ или ртути - $199\left({ }^{199} \mathrm{Hg}\right)$, у которых $\gamma$ меньше, чем у ядер углерода $-13\left({ }^{13} \mathrm{C}\right)$ и азота $-15\left({ }^{15} \mathrm{~N}\right)$.

Проведенные эксперименты показали, что учет установленных особенностей регистрации сигнала ЯМР в слабых магнитных полях в разработанном малогабаритном ЯМР-спектрометре позволил проводить исследования значительно большего числа конденсированных сред с решением различных задач (определением концентраций компонент среды, их кислотности и т.д.), чем ранее применяемых.

\section{Список литературы}

[1] Дудкин В.И., Пахомов Л.Н. // Квантовая электроника. СПб.: СПбПУ, 2012. $496 \mathrm{c}$.

[2] Камаев Р.С., Газизов Э.Г. // ЖПС. 2010. Т. 77. № 3. С. 347.

[3] Filippov A.V., Rudakova M.A., Skirda V.D. // Magn. Reson. Chem. 2012. V. 50. N 2. P. 114.

[4] Karseev A.Yu., Vologdin V.A., Davydov V.V. // J. Phys.: Conference Ser. 2015. V. 643. P. 012108.

[5] Fukuda R., Hirai A. // J. Phys. Soc. Jpn. 2013. V. 81. N 6. P. 1499.

[6] Singer J.R. // J. Phys. E: Sci. Instr. 2012. V. 45. N 1. P. 104.

[7] Жерновой А.И., Дьяченко С.В. // ЖТФ. 2015. Т. 85. В. 4. С. 118.

[8] Chiarotti G., Cristiani G., Giulotto L. // Phys. Rev. 1954. V. 93. P. 1241.

[9] Бричков А.С., Козик В.В. // Изв. вузов. Физика. 2014. Т. 57. № 7-2. С. 26.

[10] Agruzov P.M., Pleshakov I.V. // Appl. Phys. Lett. 2014. V. 104. N 7. P. 071108-4.

[11] Давыдов В.В., Величко Е.Н., Дудкин В.И., Карсеев А.Ю. // ПТЭ. 2015. № 2. C. 72 .

Письма в ЖТФ, 2017, том 43, вып. 13 
[12] Абрагам А. Ядерный магнетизм. М.: Иностр. лит., 1967. 686 с.

[13] Леше А. Ядерная индукция. М.: Иностр. лит. 1963. 684 с.

[14] Давыдов В.В., Петров А.А., Мязин Н.С. // Письма в ЖТФ. 2016. Т. 42. В. 13. C. 64.

[15] Бородин П.М., Вологдин М.И, Москалев В.В., Морозов А.А. Ядерный магнитный резонанс. Л.: Изд-во Ленингр. ун-та, 1982. 344 с. 